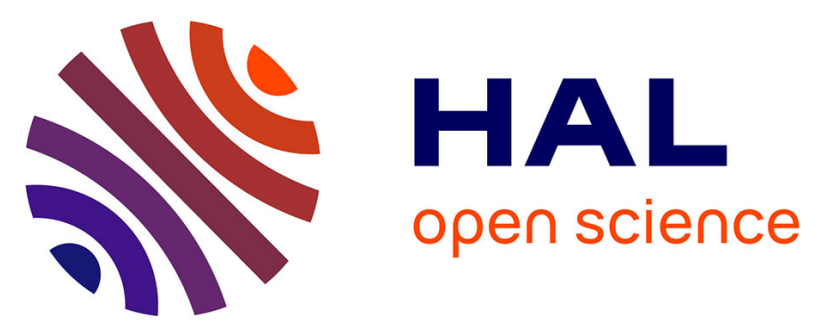

\title{
Femtosecond optical pump-probe reflectivity studies of spin-state photo-switching in the spin-crossover molecular crystals [Fe(PM-AzA)2(NCS)2]
}

\author{
Andrea Marino, Marina Servol, Roman Bertoni, Maciej Lorenc, Cindy
}

Mauriac, Jean-François Letard, Eric Collet

\section{To cite this version:}

Andrea Marino, Marina Servol, Roman Bertoni, Maciej Lorenc, Cindy Mauriac, et al.. Femtosecond optical pump-probe reflectivity studies of spin-state photo-switching in the spin-crossover molecular crystals [Fe(PM-AzA)2(NCS)2]. Polyhedron, 2013, 66, pp.123-128. 10.1016/j.poly.2013.03.009 . hal00904690

\section{HAL Id: hal-00904690}

https://hal-univ-rennes1.archives-ouvertes.fr/hal-00904690

Submitted on 15 Nov 2013

HAL is a multi-disciplinary open access archive for the deposit and dissemination of scientific research documents, whether they are published or not. The documents may come from teaching and research institutions in France or abroad, or from public or private research centers.
L'archive ouverte pluridisciplinaire HAL, est destinée au dépôt et à la diffusion de documents scientifiques de niveau recherche, publiés ou non, émanant des établissements d'enseignement et de recherche français ou étrangers, des laboratoires publics ou privés. 


\title{
Femtosecond optical pump-probe reflectivity studies of spin-state photo-switching in the spin-crossover molecular crystals [Fe(PM- $\left.\operatorname{AzA})_{2}(\mathbf{N C S})_{2}\right]$
}

\author{
Andrea. Marino ${ }^{\mathrm{a}}$, Marina Servol ${ }^{\mathrm{a}}$, Roman Bertoni ${ }^{\mathrm{a}}$, Maciej Lorenc $^{\mathrm{a}}$, Cindy Mauriac $^{\mathrm{b}}$, Jean-François Létard ${ }^{\mathrm{b}}$, \\ Eric Collet ${ }^{\mathrm{a},}$ \\ ${ }^{a}$ Institut de Physique de Rennes, UMR 6251 University Rennes 1-CNRS, Rennes, France \\ ${ }^{b}$ ICMCB, CNRS-University Bordeaux, 87 Av. du Doc. A. Schweitzer, Pessac, France \\ *e-mail: eric.collet@univ-rennes1.fr
}

\section{abstract:}

We report here on the ultrafast photo-switching dynamics of a $\mathrm{Fe}$ (II) molecular material [Fe(PM$\mathrm{AzA})_{2}(\mathrm{NCS})_{2}$ ]. It undergoes a thermal spin-crossover which can be detected by magnetic measurements or by optical reflectivity. We use here femtosecond optical reflectivity to study the ultrafast photo-switching dynamics. Our results indicate that the HS state is reached from the LS state within less than $100 \mathrm{fs}$, through an intermediate MLCT state. This ultrafast relaxation from the electronic excited state towards the structurally relaxed HS state is followed by a vibrational cooling of the hot HS molecules within $\approx 1$ ps timescale.

\section{Introduction}

Photoinduced phase transitions [1] open fascinating perspectives for controlling with light the physical properties of materials and especially molecule-based magnets. A well-known example is the Light-Induced Excited Spin State Trapping (LIESST) phenomenon [2] undergone by numerous spin-crossover (SC) compounds [3,4]. These prototype photo-active materials show photomagnetic and photochromic properties. Weak continuous wave $(c w)$ laser irradiation at low temperature is known as an efficient way for controlling SC materials by light. By choosing the appropriate excitation wavelength, one can selectively populate, the high spin (HS) state (LIESST [2a]) or low spin (LS) state (reverse LIESST [2b]), which are long-lived at low temperature. Usually, the photoinduced HS phase is similar to the HS phase observed at thermal equilibrium with similar structural reorganization, especially at the intra-molecular level [5]. More recently, light-induced symmetry breaking in the photoinduced HS phase [6] as well as transition from incommensurate HS/LS order to commensurate HS phase [7] have been also reported, illustrating that light allows access to new phases, which sometime cannot be reached at thermal equilibrium. When LIESST effect is driven by weak $c w$ laser irradiation, the switching dynamics at the macroscopic scale in crystals is limited by the photons flux: it typically occurs within few hours or minutes at low temperature. Nanosecond laser irradiation has been used on solids for driving photoinduced spin-crossover [8]. The observations of photo-switching inside thermal hysteresis represent important progress toward molecular memory devices, especially with bi-directional switching properties [3]. But despite these reports on relaxation mechanisms after nanosecond laser excitation, little has been known about the molecular transformation dynamics. Ultrafast studies of the photo-switching dynamics of single molecule in solution as shown that LS-to-HS photo-switching occurs on the sub-picosecond time scale [9]. We recently performed several studies of the ultrafast spin-state photo-switching dynamics in the $\mathrm{Fe}$ (III) solids, by using femtosecond optical spectroscopy [10] and time-resolved x-ray diffraction [11]. 
These studies have shown that the macroscopic transformation of the material driven by an intense laser pulse involves several processes driving HS conversion. In addition to the ultrafast photo-switching at the molecular scale cascading shock-wave and heating effects take place. However, the very first process involved in the photo-switching dynamics is the local trapping of the electronic excited state at the molecular level. It is now quite well established that the femtosecond pump pulse promotes instantaneously d electrons of the metal ion in the LS state to a Franck-Condon state (charge-transfer state). Transient optical absorption studies performed on molecules in solution, in solids and in nano-crystals $[9,10]$ have concluded that this electronic excited state relaxes through the intersystem crossing via different intermediate states (INT) to a state with higher parity (HS). But in the solid state, the large optical density of some SC materials does not allow using transient absorption spectroscopy for studying the photo-switching. It is the case for the dark single crystals studied here of the $\mathrm{SC} F \mathrm{Fe}$ (II) molecular material $\left[\mathrm{Fe}(\mathrm{PM}-\mathrm{AzA})_{2}(\mathrm{NCS})_{2}\right] \quad$ (i.e. cis-bis(thiocyanato)-bis(N-2'-pyridyl methylene)-4-(phenylazo) aniline iron(II) [12]). We propose therefore to use femtosecond optical reflectivity to study this photo-switching dynamics. In the first part of this paper, we demonstrate the correlation between optical reflectivity and spin-crossover observed at thermal equilibrium and in the second part we use time-resolved optical reflectivity to study the ultrafast dynamics.

\section{Thermal crossover of [Fe(PM-AzA $\left.)_{2}(\mathrm{NCS})_{2}\right]$ studied by polarized optical reflectivity}

The $\left[\mathrm{Fe}(\mathrm{PM}-\mathrm{AzA})_{2}(\mathrm{NCS})_{2}\right]$ single crystals have been characterized by magnetic measurements (Fig. 1) through the evolution of the $\chi_{M} T$ product $\left(\chi_{M}\right.$ being the magnetic susceptibility and $\mathrm{T}$ the temperature). The compound undergoes a thermal spin crossover centered at $T_{1 / 2}=189 \mathrm{~K}$ between a $\mathrm{LS}(\mathrm{S}=0)$ diamagnetic state and a $\mathrm{HS}(\mathrm{S}=2)$ paramagnetic state where the relative population of HS and LS states gradually changes with temperature from a mainly HS phase above $270 \mathrm{~K}$ to a mainly LS phase below $130 \mathrm{~K}$ [12]. As usual for SC compounds a structural reorganization is coupled to the spin conversion, characterized at the molecular level by changes of bond lengths and angles. Guionneau et al have shown that the most important changes involve the active $\mathrm{Fe}^{I I} \mathrm{~N}_{6}$ core with a contraction of $\approx 10 \%$ of the average $\langle\mathrm{Fe}-\mathrm{N}\rangle$ bond length during the HS-to-LS switching [12b].

We used optical reflectivity to figure out the fingerprints of the spin-state change at thermal equilibrium. The experiments were performed on typically $4 \times 1 \times 1 \mathrm{~mm}^{3}\left[\mathrm{Fe}(\mathrm{PM}-\mathrm{AzA})_{2}(\mathrm{NCS})_{2}\right]$ single crystals. These ones have a typical parallelepiped shape represented in Fig. 2 with two different crystallographic faces ([110] and [1-10]) almost perpendicular to each other as the system is monoclinic. The long crystal axis, which is the edge common to both faces, corresponds to the crystallographic axis $\vec{c}$. Reflectivity spectra were accumulated in [450-750] $\mathrm{nm}$ range at different temperatures by using a white-light spectrometer and a nitrogen gas flow cryostat. The thermal conversion was characterized on both crystal faces under linearly polarized light illumination. Parallel and perpendicular light polarization axes were defined with respect to the long crystal axis $\vec{c}$ (scheme in Fig 2). Reflectivity spectra of the LS and HS state, taken under perpendicular polarization, are reported in Fig. 3a. An important change of optical reflectivity spectra is observed between $130 \mathrm{~K}$ (LS state) and $270 \mathrm{~K}$ (HS state), with a well marked isosbestic point around $685 \mathrm{~nm}$. We plot in Fig $3 \mathrm{~b}$ the ratio of the reflected spectra between HS and LS states. It clearly underlines that for both faces, the reflectivity of the HS state with respect to that of LS state is higher in the visible (VIS) region and lower in the near-infrared (NIR) region, with a large difference around $660 \mathrm{~nm}$. The temperature dependence of $\Delta R / R$ at $660 \mathrm{~nm}$ is plotted in 
Fig 3c. It corresponds to the relative difference between $R(T)$, the reflectivity at a given temperature, and $R(L S)$ the reflectivity in the LS state:

$$
\frac{\Delta R}{R}=\frac{R(T)-R(L S)}{R(L S)}
$$

There is a good correlation between $\Delta R / R$ and the change of $\chi_{M} T$ product, making reflectivity change a good optical marker of the spin-state. The quality of the optical reflectivity of the large faces of the single crystals is maintained under cycling between LS and HS states. The reflectivity change are very similar for both faces and hereafter we will refer only to the analysis of the [110] face under perpendicular light irradiation for a detailed discussion. Because the crystal is monoclinic, reflectivity of light parallel or perpendicular to $\vec{c}$ axis are not equivalent by symmetry and therefore the polarization most sensitive to the change of spin state has to be identified. We found that the relative change of the reflectivity spectra measured with parallel light polarization (not shown here) shows less marked changes during the crossover. Therefore, in the following we exploit these spectroscopic fingerprints measured with perpendicular polarization, to study in real time the ultrafast photoinduced spin state switching dynamics by using femtosecond optical reflectivity.

\section{Femtosecond optical reflectivity study of the photo-switching dynamics}

\subsection{Experimental set-up}

Optical pump-probe studies are appropriate techniques to follow ultrafast dynamical process in real time. Its key point is to control the time delay $\Delta t$ between a pump pulse, which triggers the transformation, and a probe pulse, which images the photo-induced changes at different $\Delta t$ (Fig. 4). In such a way, snapshot by snapshot, a "movie" of the system evolution is obtained by monitoring the change of probe signal.

For this project, we employed two different transient absorption experiments: one kinetically resolved and the other spectrally resolved. The pump wavelength chosen here $(850 \mathrm{~nm})$, was shown to efficiently photoswitch from LS to HS states the [Fe(PM-AzA $\left.)_{2}(\mathrm{NCS})_{2}\right]$ compound, as well as different [Fe(PM-L $\left.)_{2}(\mathrm{NCS})_{2}\right]$ derivatives, where L refers to different ligands [5]. This excitation corresponds to the metal-to-ligand charge transfer (MLCT). Since the coupled molecular reorganization involves molecular and atomic motion like Fe-N stretching, with typical time scale of $\approx 130 \mathrm{fs}$, femtosecond time resolution is required to study these dynamics. In our experimental set up, the delay between the pump and probe pulses is controlled by a delay line changing the optical path length of the pump with regard to the one of the probe, with a fine timestep of $10 \mathrm{fs}$. The time resolution is then mainly limited by the laser pulse duration, and more precisely by the cross-correlation between pump and probe temporal width. The time resolution $P(t)$ of our experiment is the convolution between the Gaussian temporal dispersion of the pump $\left(\sigma_{\text {pump }}\right)$ and probe $\left(\sigma_{\text {probe }}\right)$ laser pulses and corresponds to :

$$
P(t)=\sqrt{\sigma_{\text {pump }}^{2}+\sigma_{\text {probe }}^{2}}
$$

By using a regenerative amplifier with $\approx 90$ fs Gaussian pulse duration, we are able to reach a temporal resolution with an overall instantaneous response function of $140 \mathrm{fs}$. Because we are using a stroboscopic technique with $1 \mathrm{kHz}$ repetition rate, the relaxation time of the photoinduced HS state towards the LS state should be shorter than $1 \mathrm{~ms}$ to avoid accumulating effects. This condition is fulfilled above $110 \mathrm{~K}$, where the relaxation is faster and for this reason the 
experiment was performed at $130 \mathrm{~K}$, where the crystal is in the mainly LS state (the HS fraction is around $2 \%$ ). The reflectivity change around the isosbestic point was measured by white-light spectroscopy at a time delay 10 ps after laser excitation (Fig. 5). We used then single-wavelength probe to measure the time course of the photoinduced LS-to-HS transformation, through the relative reflectivity change $(\Delta R / R)$ in identified spectral zones (Fig. 6) around the isobestic point, where reflectivity is expected to increase below $685 \mathrm{~nm}$ and decrease above as HS state is formed (Fig. 3).

\subsection{Results}

The reflectivity change spectra of the photoinduced state measured 10 ps after laser excitation are shown for both faces in Fig. 5. In each of them it is observed that reflectivity increases in VIS part and a decreases in the NIR parts, with an isosbestic point found around $685 \mathrm{~nm}$. This is a direct signature of the photoinduced HS state as the changes observed obey the spectral behavior resulting from LS-to-HS switching observed at thermal equilibrium (Fig 3). We now discuss how the clear optical fingerprint of the photoswitching from LS to HS states evolves in the time domain and on which time scale the HS state is formed.

For studying this photo-switching dynamics, additional measurements were performed in the time domain by using different monochromatic probes. Selected time traces are plotted in Fig. 6, indicating two main steps:

- a very short transient peak ( $<100 \mathrm{fs}$, observed at $695 \mathrm{~nm}$ ) and associated with fast changes of reflectivity immediately after laser excitation;

- a slower ( $\approx 1 \mathrm{ps}$ ) relaxation towards a plateau (observed at 635 and $660 \mathrm{~nm}$ ).

This two-step photo-switching process is very similar to the studies reported by transient absorption spectroscopy for SC molecules in solution or in nano-crystals [9, 10a].

We can use here the same simple model to take into account the two different dynamics. The increase of reflectivity at $695 \mathrm{~nm}$, just after laser excitation, is not an optical fingerprint of the HS state as this wavelength corresponds to the isosbestic point of LS and HS species. This peak characterizes therefore the intermediate (INT) electronic excited state (including MLCT and other possible intermediates).

The population of the MLCT state is too fast to be observed here and therefore the first dynamics we observe is the population of HS state by depopulation of the INT electronic states. This process is associated with a time constant $\tau_{1}$ (which is less than $100 \mathrm{fs}$ ), as schematically shown in Fig 7. The second process involved is the vibrational cooling of the HS state, associated with a longer time constant $\tau_{2}$ (of the order of $1 \mathrm{ps}$ ). Indeed, a huge excess of energy is deposited on the molecule by the absorbed photon $(1.46 \mathrm{eV})$, since the energy difference between the LS and HS states is of the order of the thermal energy (20 meV). After 100s fs, most of the absorbed energy is still localized at the molecular level.

For obtaining accurate time constants, fits of the time traces were performed with the biexponential model (solid lines in Fig. 6), by taking into account the $140 \mathrm{fs}$ instantaneous response function of our experimental set-up. As a result, it is possible to deconvoluate these time traces and obtain the time dependence of the photoinduced INT (green line) and HS species (red line) as shown in Fig. 7. The different fits gave $\tau_{1}<100 \mathrm{fs}$, in agreement with earlier reports on SC metal complex in solution [9] or in crystals [10]. It was underlined that the relaxation from the INT states towards the HS state is the bottleneck for the relaxation process and that $\tau_{1}$ does not vary with the probe wavelength. This is not the case for $\tau_{2}$, which is observed here to be in the [500- 
$2000 \mathrm{fs}$ ] range for the different probe wavelengths used. Vibrational cooling corresponds to the slower increase of reflectivity at $660 \mathrm{~nm}$ and decrease at $635 \mathrm{~nm}$ after the stepped-like change following the photo-excitation. This slower change of optical properties results from optical band narrowing [10a and references therein], a well-known marker of vibrational cooling. The probe wavelength dependence of the time-scale of this second process is therefore only apparent.

\section{Conclusion}

Light-control over molecular systems and especially molecular magnet is a key topics of interest. Up to now, studies have been mainly limited to slow kinetics, induced by weak $c w$ laser excitation. Ultrafast transient absorption spectroscopy was used to study molecules in solution or (nano) crystals by transient absorption spectroscopy $[9,10]$. Here we demonstrate that transient optical reflectivity can also be used on single crystals for revealing the ultra-fast photoinduced processes, as clear optical markers of the different spin states can be obtained.

Our conclusion on the LS-to-HS photoswitching dynamics is that it takes less than 100 fs for populating the HS state. Indeed, for moving from the LS potential to the HS potential, Fe-N bond lengths have to expand. This dynamics is limited by the intrinsic time-scale of Fe- $\mathrm{N}$ expansion, which occurs when $d$ electrons are removed from the $t_{2 g}$ orbitals in the LS state. The time-scale can be estimated from the Fe-N stretching mode in the HS state, which is observed at $255 \mathrm{~cm}^{-1}$ in $\left[\mathrm{Fe}(\mathrm{PM}-\mathrm{AzA})_{2}(\mathrm{NCS})_{2}\right][13]$ and corresponds to a period of $130 \mathrm{fs}$. This time-scale is of the same order as what we found here and indicates that it is the structural molecular reorganization inside the potential energy surface which limits the LS-to-HS transformation. The vibrational cooling, which we found here to occur within $\approx 1$ ps corresponds well to the process discussed in the literature of SC systems, being molecules in crystals or in solution. The only difference is that vibrational cooling is slower in solution. This is very likely due to the less efficient dissipation of the excess energy to the environment: in solids lattice phonons allow an efficient coupling of the locally excited molecules with the environment, whereas in solution molecule has to transfer the excess energy to the solvent.

It should be underlined that in addition to Fe-based SC materials studied here, optical reflectivity or absorption can be used to study the photo-switching process involved in other types of photoactive molecule-based magnets. Of course, ultrafast spectroscopy can be applied to study LIESST effect in SC materials based on other metal ions, like $\mathrm{Cu}$ [14], Mn [15] or others. But ultrafast studies are also of interest for other types of photomagnetic materials where electronic and structural degrees of freedom are strongly coupled. Among them, we can mention charge-transfer (CT) systems like Fe-Co molecular materials [16] or Prussian Blue analogues [17], whose photoswitching process is associated with different types of dynamics. In addition to understanding the photoswitching pathway were different types of electronic and structural degrees of freedom will be involved, one of the fundamental points of interest is to know if (and how) the localized CT process can drive switching of adjacent active sites. This is also an open question for bi-nuclear or multi-nuclear SC systems.

Acknowledgement:

This work was supported by the CNRS, the Institut Universitaire de France, Rennes Métropole, Région Bretagne (CREATE 4146), the ANR (09-BLAN-0212) and Europe (FEDER).

Keywords: Spin crossover $\bullet$ Femtochemistry $\bullet$ LIESST $\bullet$ Phase transitions $\bullet$ Laser spectroscopy $\bullet$

\section{References}


[1] A. Lewanowicz, T. Luty, Photo-Induced Phase Transition and Cooperative Phenomena, Acta Physica Polonica A, 121 (2012) 291-378.

[2] (a) S. Decurtins, P. Gütlich, C. P. Köhler, H. Spiering, and A. Hauser, Chem. Phys. Lett. 105 (1984) 1;

(b) A. Hauser, Chem. Phys. Lett., 124 (1986) 543;

(c) A. Bousseksou, G. Molnar, L. Salmon, W. Nicolazzi, Chem. Soc. Rev. 40 (2011) 33133335.

[3] (a). J.-F. Létard, P. Guionneau, O. Nguyen, J. S. Costa, S. Marcén, G. Chastanet, M. Marchivie, L. Capes, Chem. Eur. J., 11 (2005) 4582;

(b) J.-F. Létard, J. Mater. Chem., 16 (2006), 2550;

[4] (a) A. Hauser, J. Jeftic, H. Romstedt, R. Hinek, and H. Spiering, Coord. Chem. Reviews, 190-192 (1999) 471-491;

(b) E. Trzop, M. B. L. Cointe, H. Cailleau, L. Toupet, G. Molnar, A. Bousseksou, A. B. Gaspar, J. A. Real, E. Collet, J. Appl. Cryst. 40 (2007) 158-164;

(c) J.-F. Létard, P. Guionneau, L. Rabardel, J.A.K. Howard, A.E. Goeta, D. Chasseau, O. Kahn, Inorg. Chem., 37 (1998) 4432;

(d) J.-F. Létard, L. Capes, G. Chastanet, N. Moliner, S. Létard, J.A. Real, O. Kahn, Chem. Phys. Lett., 313 (1999) 115;

(e) S. Marcén, L. Lecren, L. Capes, H. A. Goodwin, J.-F. Létard, Chem. Phys. Lett., 358 (2002) 87;

(f) S. Ohkoshi, K. Imoto, Y. Tsunobuchi, S. Takano, H. Tokoro, Nature Chem. 3 (2011) 564-569;

(g) M. Griffin, S. Shakespeare, H. J. Shepherd, C. J. Harding, J.-F. Létard, C. Desplanches, A. E. Goeta, J. A. K. Howard, A. K. Powell, V. Mereacre, Y. Garcia, A. D. Naik, H. Müller-Bunz, G. G. Morgan, Angew. Chem. Int. Ed. 50 (2011) 896-900;

(h) C. Chong, M. Haritosh, K. Boukheddaden, S. Denise, G. Bouchez, E. Collet, J.C. Ameiline, A. Naik, Y. Garcia, F. Varret, J. Phys. Chem. B 114 (2010) 1975-1984

[5] (a) M. Marchivie, P. Guionneau, J.A.K. Howard, G. Chastanet, J.-F. Létard, A.E. Goeta,

D. Chasseau, J. Amer. Chem. Soc., 124 (2002) 194-196;

(b) M. Marchivie, P. Guionneau, J.-F. Létard, D. Chasseau, Acta Cryst. B, 61 (2005) 2528;

(c) M. Buron-Le Cointe, J. Hébert, Ch Baldé, N. Moisan, L. Toupet, P. Guionneau, J.-F. Létard, E. Freysz, H. Cailleau, E. Collet, Phys. Rev. B 85 (2012) 064114.

[6] (a) N. Bréfuel, H. Watanabe, L. Toupet, J. Come, N. Matsumoto, E. Collet, K. Tanaka, J.P. Tuchagues, Angew. Chem. Int. Ed. 48 (2009) 9304-9307;

(b) N. Bréfuel, E. Collet, H. Watanabe, M. Kojima, N. Matsumoto, L. Toupet, K. Tanaka, and J. P. Tuchagues, Chem. Eur. J. 16 (2010) 14060.

(c) H. Watanabe, N. Bréfuel, E. Collet, L. Toupet, K. Tanaka, J.-P. Tuchagues, Eur. J. Inorg. Chem. 5-6, (2013) 710-715

[7] E. Collet, H. Watanabe, N. Bréfuel, L. Palatinus, L. Roudaut, L. Toupet, K. Tanaka, J.-P. Tuchagues, P. Fertey, S. Ravy, B. Toudic, H. Cailleau. Phys. Rev. Lett. 109 (2012) 257206.

[8] (a) J. Degert, N. Lascoux, S. Montant, S. Létard, E. Freysz, G. Chastanet, J.-F. Létard, Chem. Phys. Lett., 415 (2005) 206-210;

(b) E. Freysz, S. Montant, S. Létard, J.-F. Létard, Chem. Phys. Lett., 394 (2004) 318-323;

(c) S. Cobo, D. Ostrovskii, S. Bonhommeau, L. Vendier, G. Molnar, L. Salmon, K. Tanaka, A. Bousseksou, J. Am. Chem. Soc. 130 (2008) 9019-9024; 
(d) S. Bedoui, M. Lopes, W. Nicolazzi, S. Bonnet, S. Zheng, G. Molnár, A. Bousseksou, Phys. Rev. Lett. 109 (2012) 135702;

(e) G. Galle, J. Degert, C. Mauriac, C. Etrillard, J.F. Letard, E. Freysz, Chem. Phys. Lett. 500 (2010) 18-22.

[9] (a) C. Consani, M. Prmont-Schwarz, A. ElNahhas, C. Bressler, F. van Mourik, A. Cannizzo, M. Chergui, Angew. Chem. Int. Ed. 48 (2009) 7184 -7187;

(b) W. Gawelda, A. Cannizzo, V.T. Pham, F. van Mourik, C. Bressler, M. Chergui, J. Am. Chem. Soc. 129 (2007)8199-8206;

(c) A.L. Smeigh, M. Creelman, R.A. Mathies, J.K. McCusker, J. Am. Chem. Soc. 130 (2008) 14105-14107;

(d) J. Tribollet, G. Galle, G. Jonusauskas, D. Deldicque, M. Tondusson, J.F. Letard, E. Freysz, Chem. Phys. Lett. 513 (2011) 42-47;

(e) M.M.N. Wolf, R. Groß, C. Schumann, J.A. Wolny, V. Schünemann, A. Døssing, H. Paulsen, J.J. McGarvey, R. Diller, Phys. Chem. Chem. Phys. 10 (2008) 4264-4273;

(f) M. Chergui, Dalton Trans. 41 (2012) 13022-13029;

(g) E.A. Juban, J.K. McCusker, J. Am. Chem. Soc. 127 (2005) 6857-6855.

[10] (a) R. Bertoni, M. Lorenc, A. Tissot, M. Servol, M.-L. Boillot, E. Collet E. Angew. Chem. Int. Ed. 51 (2012) 7485-7489;

(b) W. Kaszub, M. Buron-Le Cointe, M. Lorenc, M.-L. Boillot, M. Servol, A. Tissot, E. Collet, Eur. J. Inorg. Chem. 5-6 (2013) 992-1000;

(c) A. Tissot, R. Bertoni, E. Collet, L. Toupet, M.L. Boillot, J. Mater. Chem. 21 (2011) 18347-18353;

(d) N. Moisan, M. Servol, M Lorenc, A. Tissot, M.-L. Boillot, H. Cailleau, S. Koshihara, E. Collet, C. R. Chim. 11 (2008) 1235-1240;

(e) M. Lorenc, Ch Balde, W. Kaszub, A. Tissot, N. Moisan, M. Servol, M. Buron-Le Cointe, H. Cailleau, P. Chasle, P. Czarnecki, M.L. Boillot, E. Collet, Phys. Rev. B. 85 (2012) 054302.

[11] (a) M. Lorenc, J. Hébert, N. Moisan, E. Trzop, M. Servol, M. Buron-Le Cointe, H. Cailleau, M.L. Boillot, E. Pontecorvo, M. Wulff, S. Koshihara, E. Collet, Phys. Rev. Lett. 103 (2009) 028301;

(b) H. Cailleau, M. Lorenc, L. Guérin, M. Servol, E. Collet, M. Buron-Le Cointe, Acta Cryst. A 66 (2010) 133-134;

(c) E. Collet, M. Lorenc, M. Cammarata, L. Guérin, M. Servol, A. Tissot, M.-L. Boillot, H. Cailleau, M. Buron-Le Cointe, Chem. Eur. J. 18 (2012) 2051 - 2055;

(d) E. Collet, N. Moisan, C. Baldé, R. Bertoni, E. Trzop, C. Laulhé, M. Lorenc, M. Servol, H. Cailleau, A. Tissot, M.-L. Boillot, T. Graber, R. Henning, P. Coppens, M. Buron-Le Cointe, Phys. Chem. Chem. Phys. 14 (2012) 6192-6199.

[12] P. Guionneau, J.F. Létard, D. Yufit, D. Chasseau, G. Bravic, A.E. Goeta, J.A. Howard and O. Kahn, J. Matter. Chem. 9 (1999) 985-994;

(b) P. Guionneau, M. Marchivie, G. Bravic, J.-F. Létard, D. Chasseau "Structural aspects of spin crossover", Eds. P. Gütlich et H.A. Goodwin "Spin Crossover in Transition Metal Compounds", Topics in Current Chemistry, Springer WienNewYork, 234 (2004) 97-128.

[13] A. Hoefer, PhD Thesis, University of Mainz, 2000.

[14] M. V. Fedin, E. G. Bagryanskaya, H. Matsuoka, S. Yamauchi, S.L. Veber, K. Yu. Maryunina, E. V. Tretyakov, V. I. Ovcharenko, R. Z. Sagdeev, J. Am. Chem. Soc. 134 (2012) 16319-16326. 
[15] G. G. Morgan, K. D. Murnaghan, H. Müller-Bunz, V. McKee, C. J. Harding, Angew. Chem. Int. Ed. 45 (2006) 7192-7195.

[16] (a) Y. Zhang et al., Angew. Chem. Int. Ed. 49 (2010) 3752;

(b) D. Siretanu et al., Chem. Eur. J. 17 (2011) 11704.

[17] M. Clemente-Leon, E. Coronado, A. Lopez-Munoz, D. Repetto, C. Laure, Mallah Talal Langmuir 28 (2012) 4525-4533. 


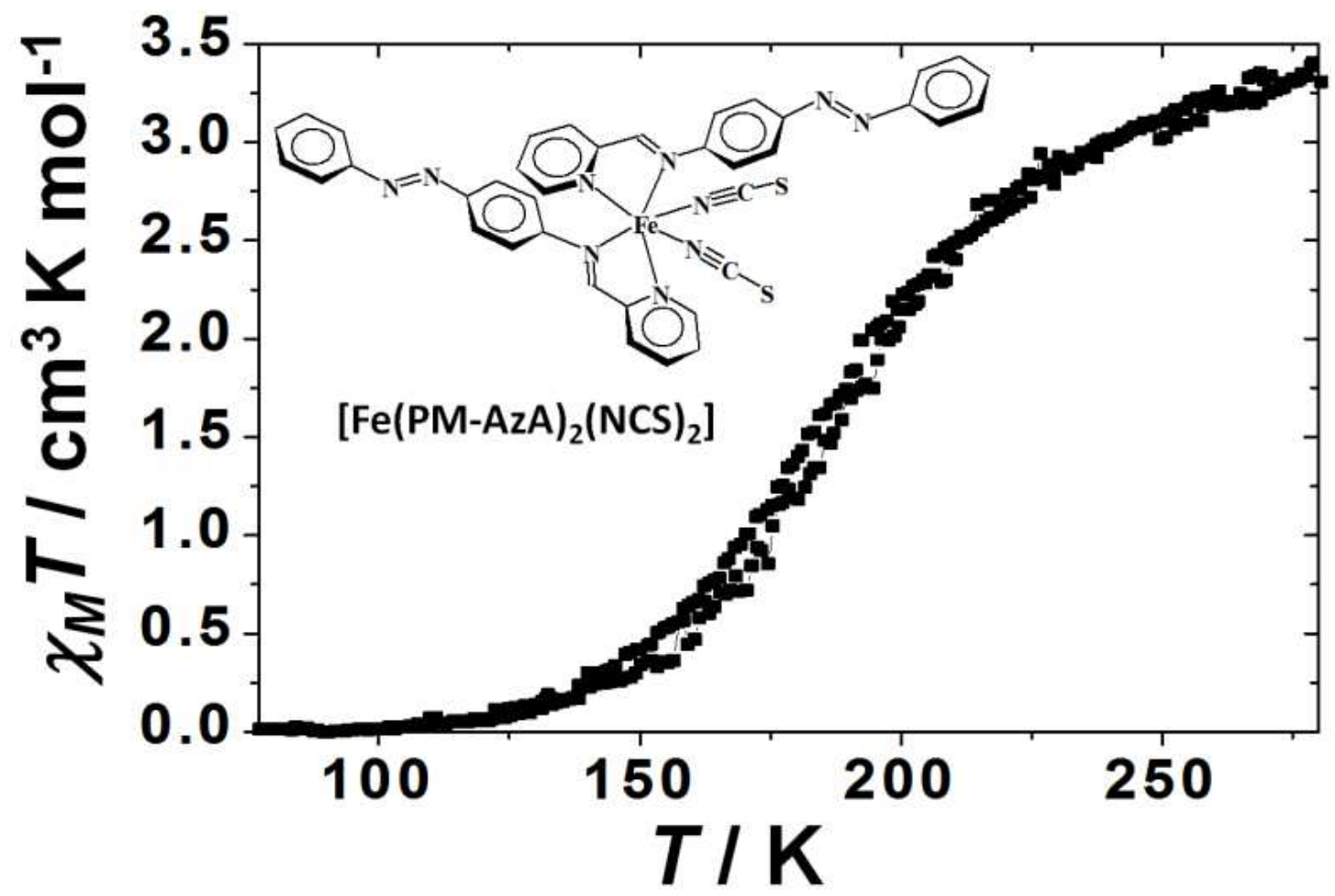

Fig. 1 The $\left[\mathrm{Fe}(\mathrm{PM}-\mathrm{AzA})_{2}(\mathrm{NCS})_{2}\right]$ compound and its thermal spin-crossover characterized by magnetic susceptibility. 

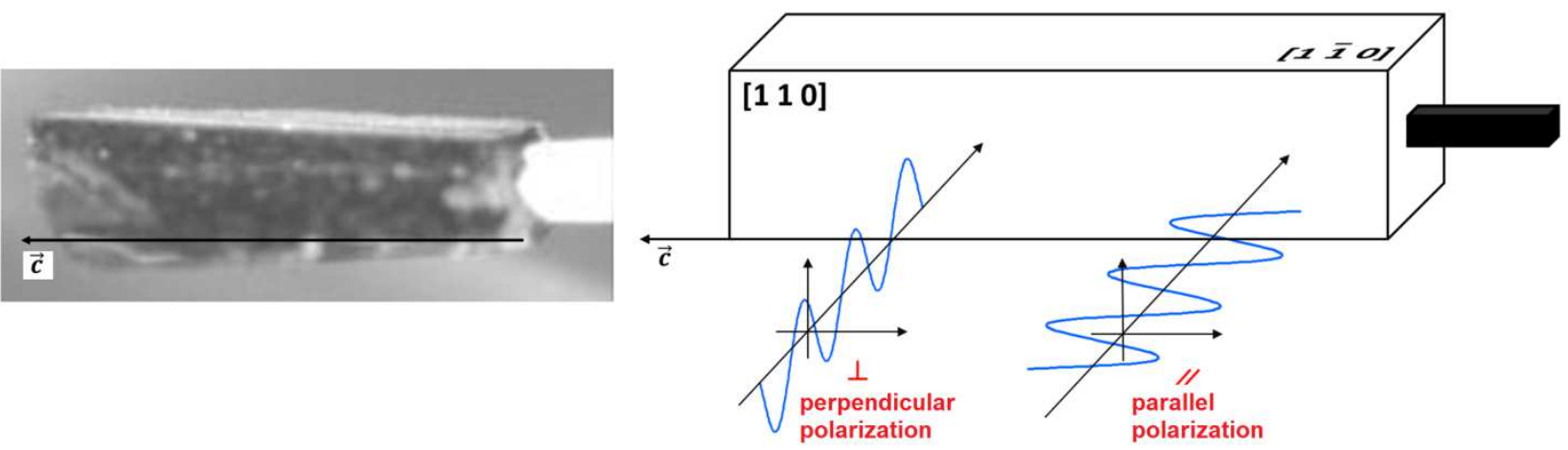

Fig. 2 Photograph of the crystal (left) and schematic drawn of the two indexed faces and light polarization direction. 
[110]

a)

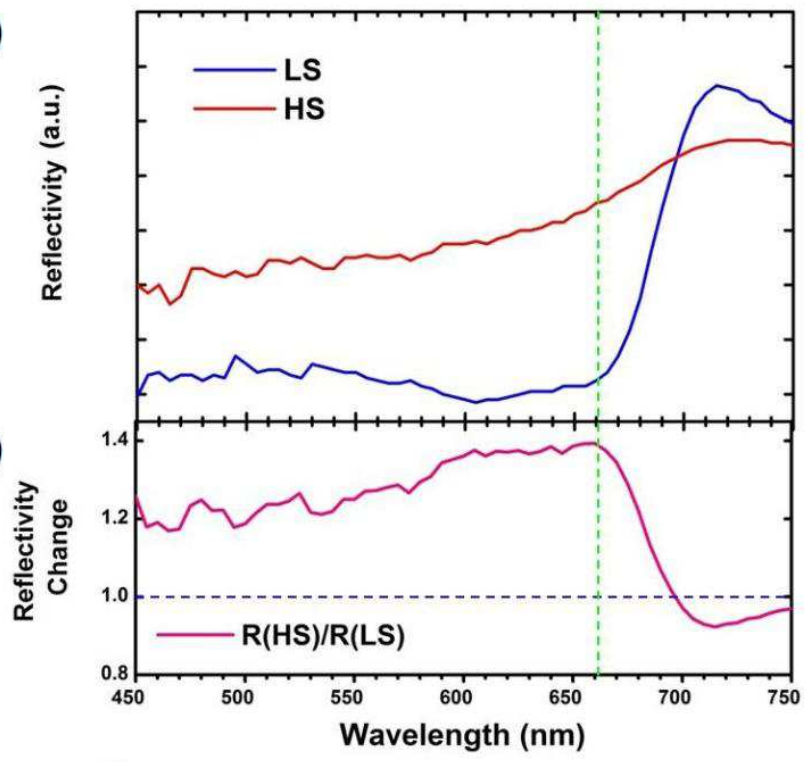

c)

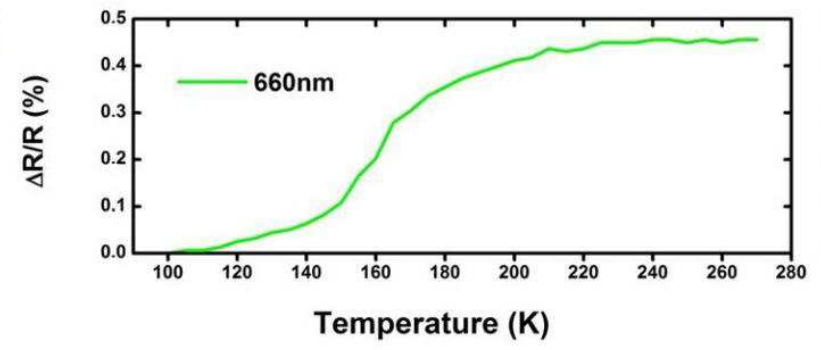

[110]
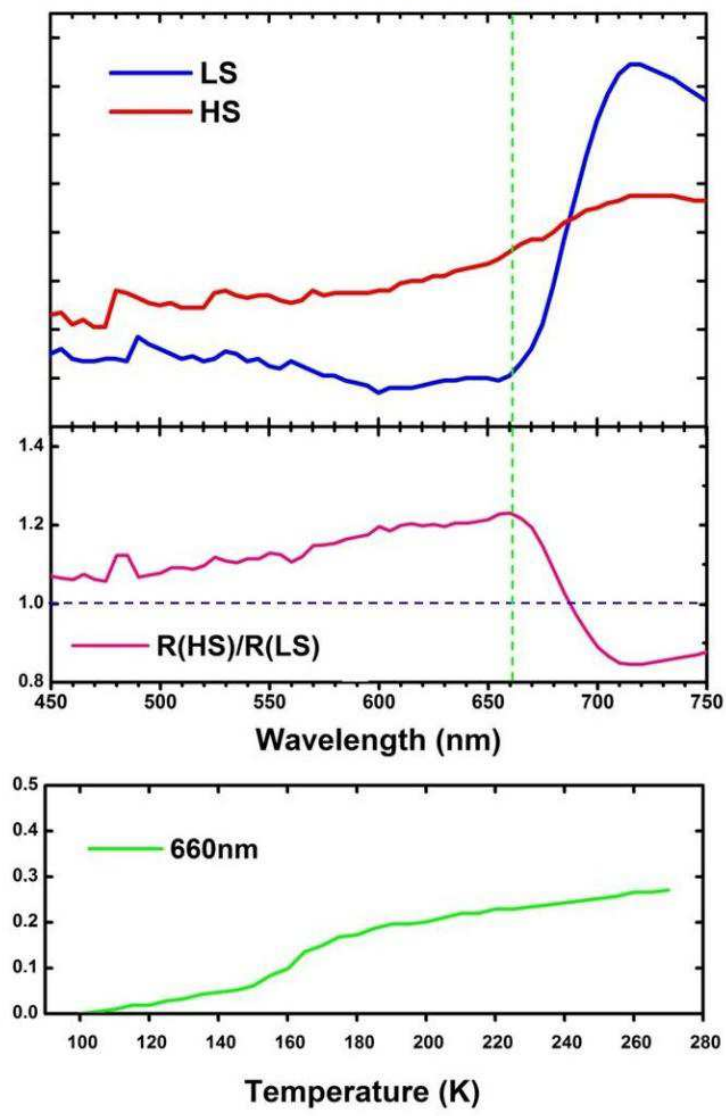

Fig. 3 (a) Thermal variation of the optical reflectivity during the LS (130 K) to HS (270 K) thermal conversion, measured with light polarization perpendicular to the long crystal axis $c$ for $\left[\begin{array}{lll}1 & 1 & 0\end{array}\right]$ (left) and $\left[\begin{array}{lll}1 & -1 & 0\end{array}\right]$ (right) faces. (b) Ratio of the reflectivity spectra of HS and LS states. (c) Temperature dependence of the relative reflectivity change with respect to the LS state at $100 \mathrm{~K}$ at $660 \mathrm{~nm}$ for both faces. 


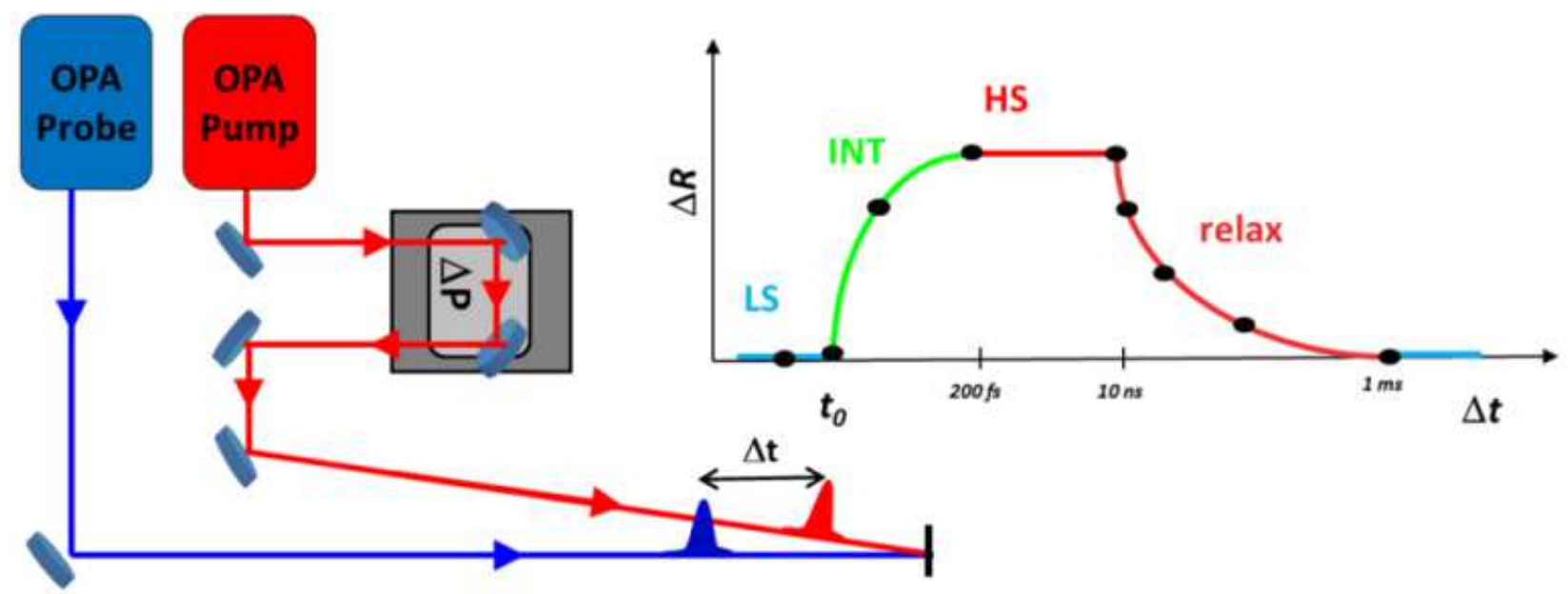

Fig. 4 Schematic pump-probe set-up consisting in monitoring the change of reflectivity $\Delta R$ with a probe pulse delayed by $\Delta t$ from the pump pulse. 


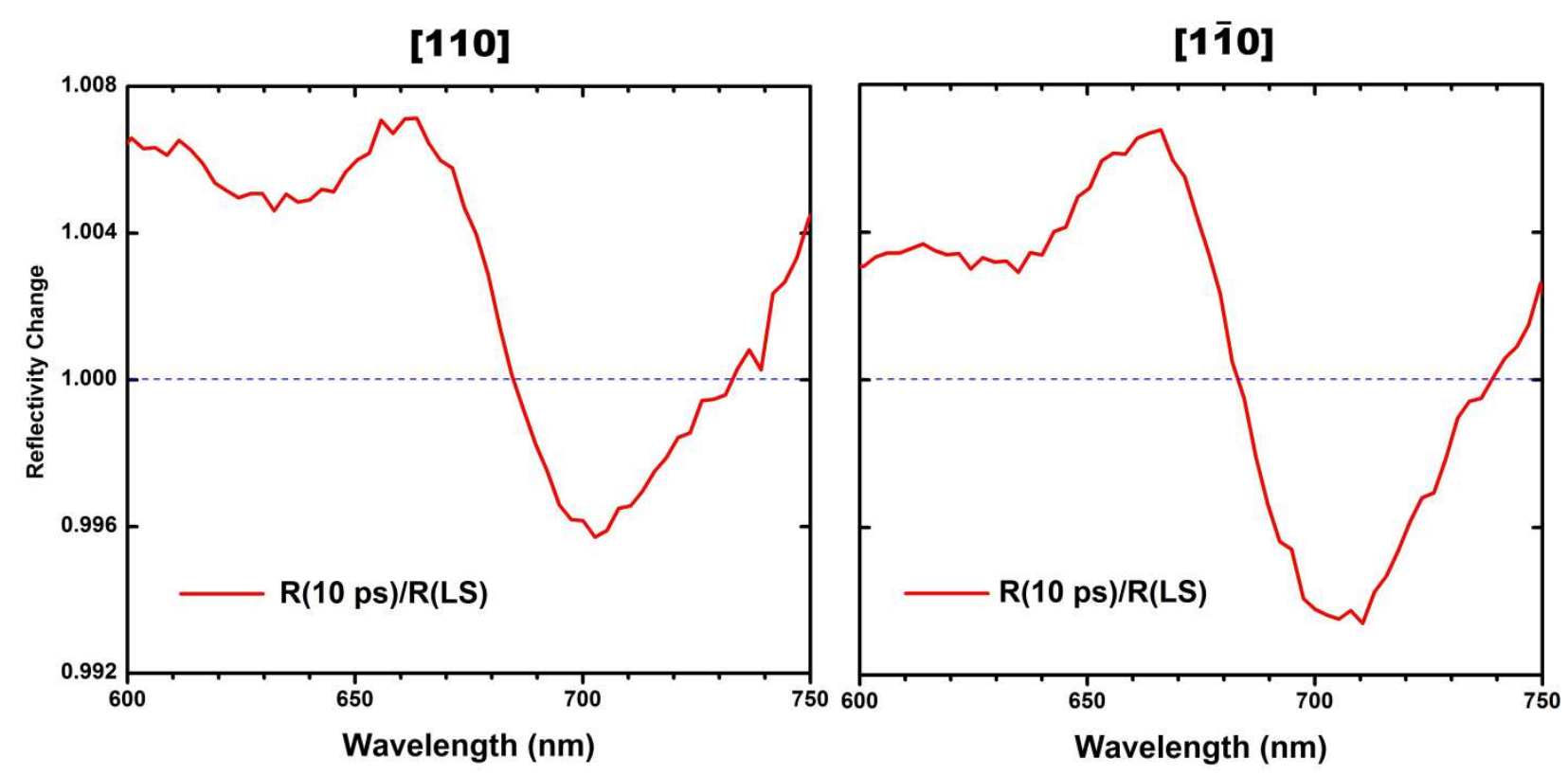

Fig. 5 Relative change of reflectivity between the LS and photoinduced HS states measured 10 ps after laser excitation by white-light spectroscopy for face [ $\left.\begin{array}{lll}1 & 1 & 0\end{array}\right]$ and $\left[\begin{array}{lll}1 & -1 & 0\end{array}\right]$. 


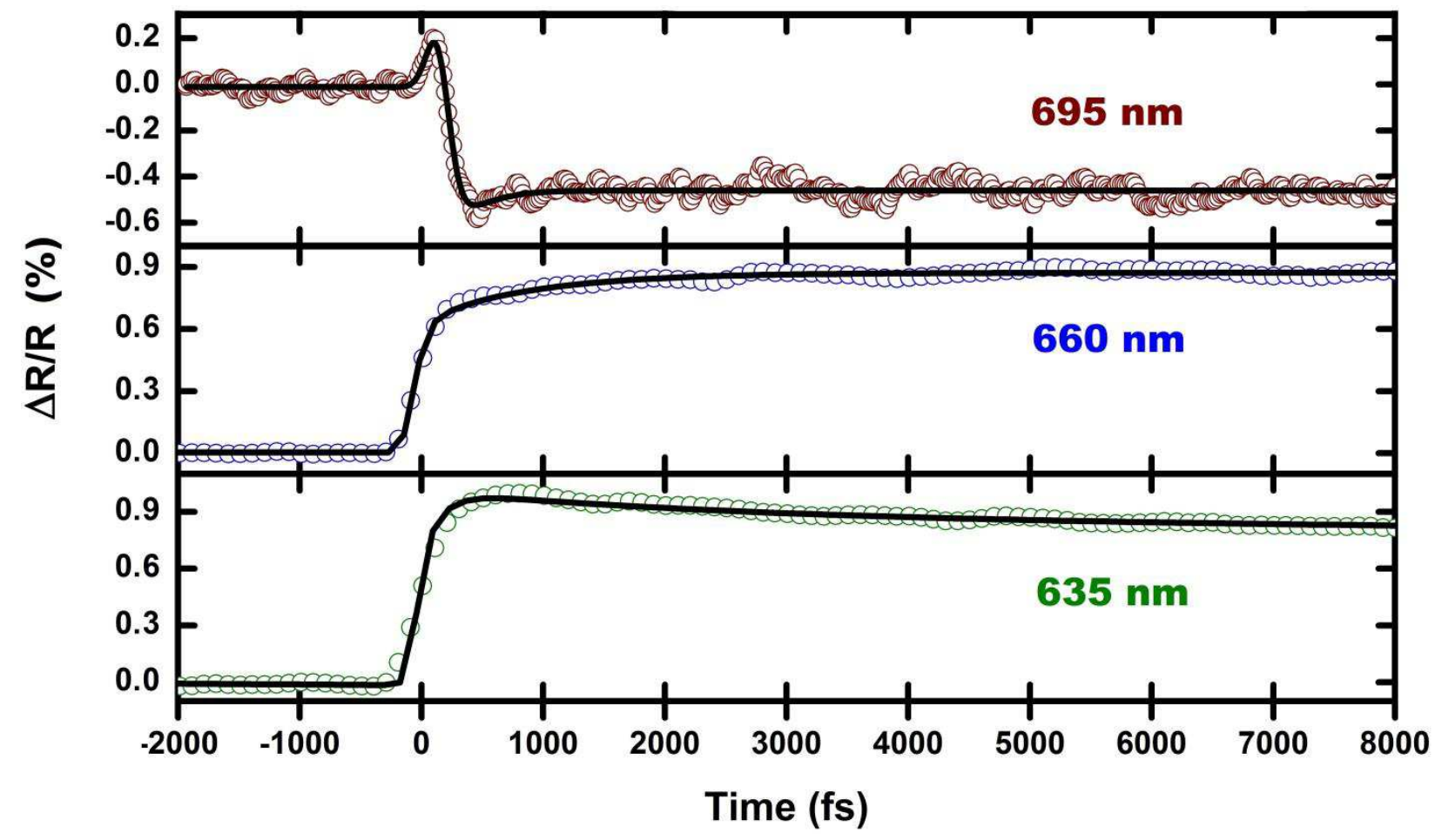

Fig 6: Raw data (symbols) of the kinetic traces of relative reflectivity at 635, 660 and $695 \mathrm{~nm}$ following fs laser excitation. Solid lines show the results of the fitting procedure taking into account a time constants $\tau_{1}$ for the relaxation of short-lived intermediate states (INT), and $\tau_{2}$ for the vibrational cooling of the photoinduced HS state. 

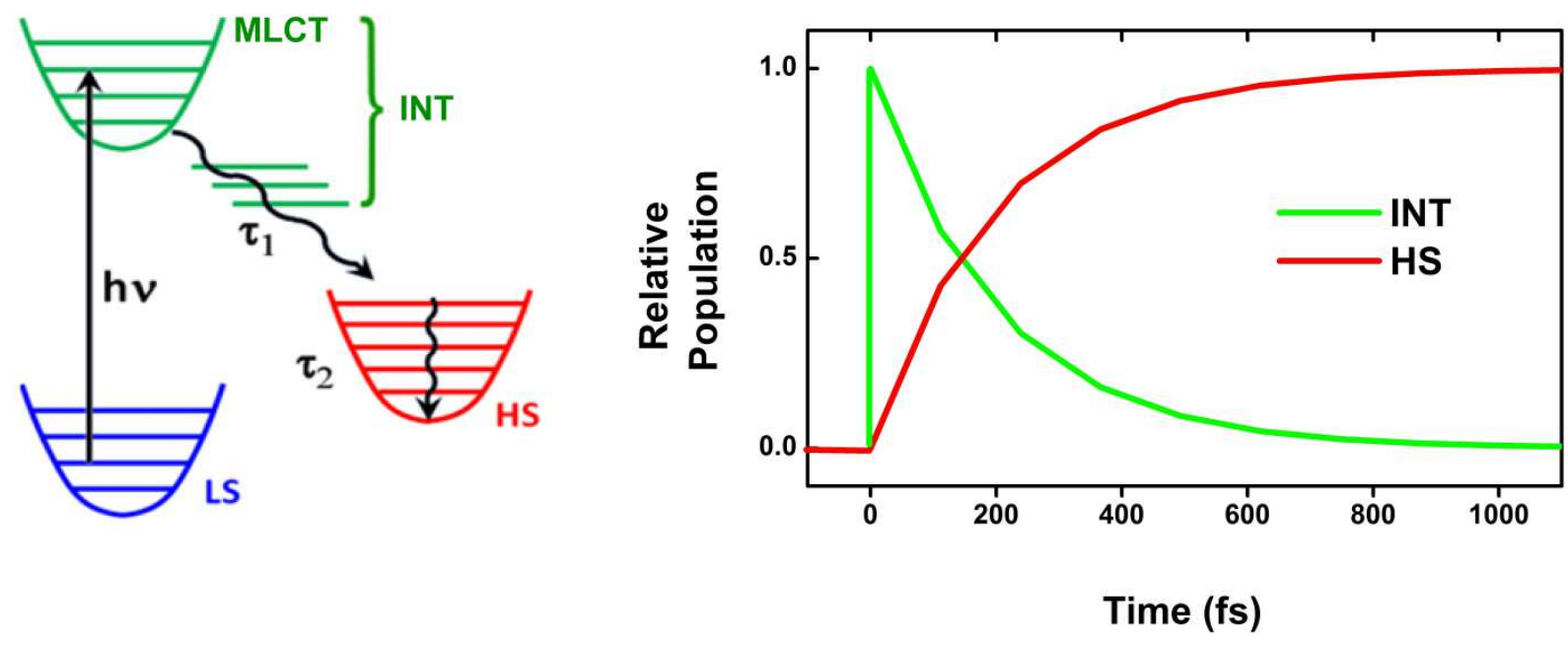

Fig 7: (left) Schematic photo-switching pathway (left) with time constants $\tau_{1}$ for the relaxation of short-lived intermediate states (INT), and $\tau_{2}$ for the vibrational cooling of the photoinduced HS state. (right) Kinetic relative population of the INT (green) and HS (red) states (solid line) of photo-excited molecules deconvoluted from experimental data in Fig. 6. 

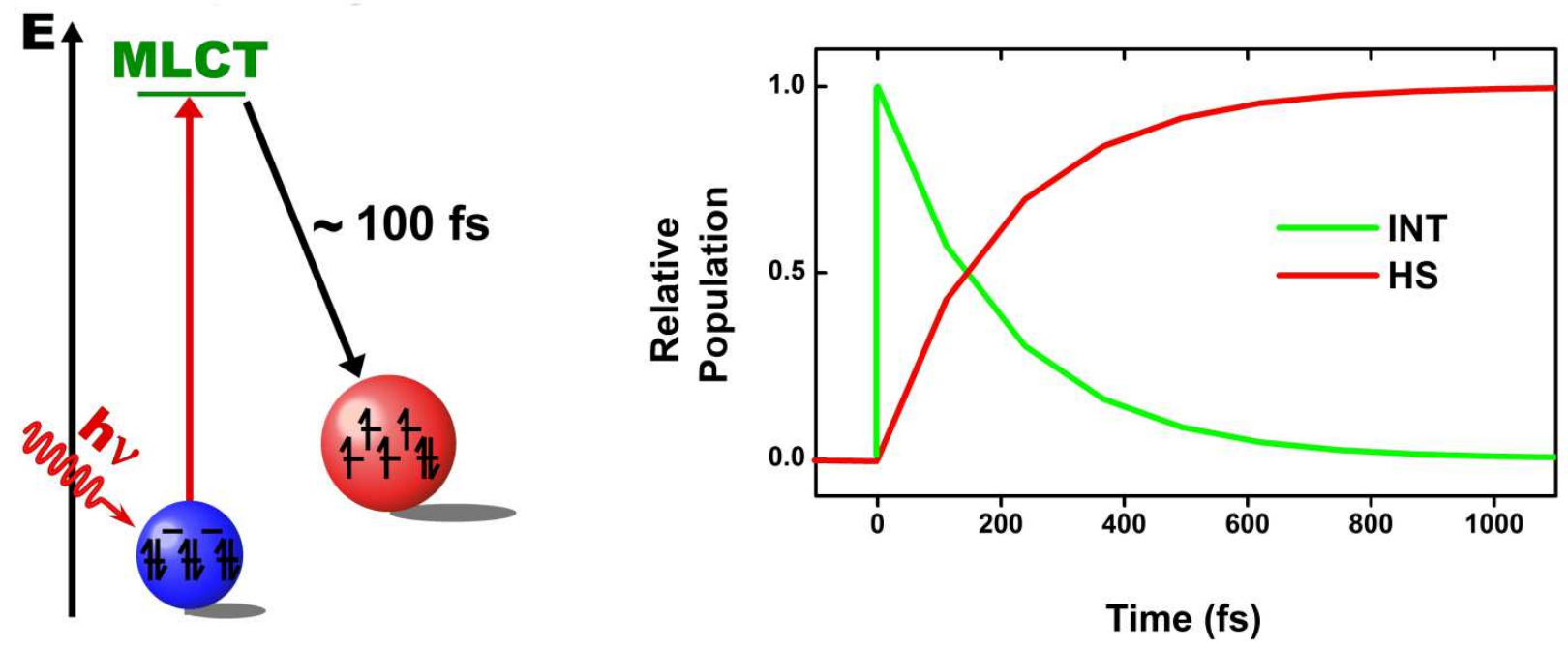

Synopsis: Femtosecond optical reflectivity is used to study ultrafast photo-switching dynamics in a spincrossover solid. 